\title{
Characterization of the Bulk Flow Properties of Industrial Powders from Shear Tests
}

\author{
Domenico Macri ${ }^{1}{ }^{(0)}$, Roberto Chirone ${ }^{1}$, Hamid Salehi ${ }^{2}$, Daniele Sofia ${ }^{2}$, \\ Massimiliano Materazzi ${ }^{1}$, Diego Barletta ${ }^{2}\left(\mathbb{D}\right.$, Paola Lettieri ${ }^{1}$ and Massimo Poletto ${ }^{2, *(1)}$ \\ 1 Department of Chemical Engineering, University College London, Torrington Place, London WC1E 7JE, UK; \\ domenico.macri@ucl.ac.uk (D.M.); roberto.chirone.13@ucl.ac.uk (R.C.); \\ massimiliano.materazzi.09@ucl.ac.uk (M.M.); p.lettieri@ucl.ac.uk (P.L.) \\ 2 Dipartimento di Ingegneria Industriale, Università degli Studi di Salerno, Via Giovanni Paolo II, 132, \\ 84084 Fisciano (SA), Italy; hsalehikahrizsangi@unisa.it (H.S.); dsofia@unisa.it (D.S.); dbarletta@unisa.it (D.B.) \\ * Correspondence: mpoletto@unisa.it
}

Received: 31 March 2020; Accepted: 28 April 2020; Published: 5 May 2020

\begin{abstract}
Bulk flow properties from shear analysis of compacted powders can be evaluated following different approaches. Experimental values of shear stresses obtained by conventional shear cells are traditionally used to build yield loci, from which the most relevant flow properties could be found. Such flow properties play an important role in determining their performance under fluidization conditions. In this work, a useful app, named cYield, was developed by using the new Matlab's App Developer environment. This tool enables users to calculate both linear (Coulomb) and non-linear (Warren-Spring) yield loci as the best fitting of the $\sigma$ - $\tau$ experimental shear points. It also provides a wide range of statistical information related to the quality of the outcomes obtained. The different features of the tool are presented, and the crucial steps for the execution of its calculations are illustrated. Moreover, it has been applied for the yield loci analysis of four different materials traditionally used in manufacturing processes. The results confirm that the flow behavior of many industrial powders, especially if cohesive, is better described by a non-linear yield locus.
\end{abstract}

Keywords: powder characterization; flowability; Matlab App; yield locus; tensile strength

\section{Introduction}

Particulate solids are widely used in industry, from powder coating to food, from nanoscale powders and pharmaceuticals to products like cement, coal, and ore, from dry materials like fly ash to moist bulk solids like filter cake and clay [1]. As all these substances have to be transported, conveyed or handled, there is a massive need for information about their handling and flow characteristics. Particle science and technology are therefore essential to both the improvements of many manufacturing processes and also to tackle most contemporary grand challenges, such as in advanced manufacturing, sustainable energy, waste management and food preservation.

Within this framework, extensive research has been carried out over the last sixty years to define and measure parameters apt to characterize and predict the flow properties of solid materials [2-7]. Many methods and testers exist to measure the flow properties of bulk solids, but shear cells are currently the most used devices [8-10]. Some authors related the powders' shearing behavior to their performance when used in a fluidized bed. They demonstrated that the intrinsic powders' flow properties have a significant effect on the pressure drop, expansion profiles and fluidization quality of the investigated materials [11-16].

Powders' flow behavior is commonly described in engineering science by using a continuum mechanics methodology, which allows for the direct characterization of powders' rheological properties and flowability, by estimating the stress distribution within powders at failure [17]. 
The stress distribution inside a bulk solid is usually described by combining both yield locus and Mohr circles analysis. The first one is aimed at determining the limiting shear stresses under any normal stress when failure or, more precisely, incipient flow occurs. In several applications, it is assumed that the powder behaves like a solid at failure. Therefore, the local state of stresses can be represented in the normal-shear stresses plane ( $\sigma-\tau$ plane) by Mohr circles tangent to the yield locus. The major principal stress named $\sigma_{1}$ is the one occurring during consolidation. It is usually considered that the Mohr circle representing the state of stress during the material consolidation in the critical state shear closes the yield locus on the consolidation side. Therefore, $\sigma_{1}$ is estimated from the largest intercept on the $\sigma$ axis of the Mohr circle tangent to the yield locus and passing through the consolidation point. The unconfined yield strength, $f_{c}$, is the material strength under unconfined uniaxial compression and, therefore, corresponds to the finite intercept on the $\sigma$ axis of the Mohr circles, which is tangent to the yield locus line and passes through the origin of $\sigma-\tau$ plane. The unconfined yield strength represented as a function of the major principal stress is the so-called "flow function".

Another significant flow property for granular materials is the tensile strength, $\sigma_{\mathrm{t}}$. It represents the resistance stress necessary to separate two layers of materials by means of an isostatic tensile strain. Despite its direct experimental measurement, which is not standardized, the tensile strength is represented by the intersection between the negative side of the $\sigma$-axis and the yield locus. In powders, it is the evident macroscopic manifestation of the attractive forces between the constituent particles. Like cohesion and unconfined yield strength, a finite value of the tensile strength is possible only if attractive interparticle interactions are present. Cohesion, unconfined yield strength and tensile strength are macroscopic evidence of attractive of interparticle forces, such as van der Waals, electrostatic and capillary forces, which depend on the state of powder consolidation that, in turn, is a function on the packing state of the powder and the stress history [10].

The yield locus analysis that, starting from the experimental shear data, allows us to estimate all the above mentioned flow properties can be conducted by using two different approaches. The first one is the Mohr-Coulomb analysis, in which a straight line represents the yield conditions in the $\sigma-\tau$ plane, as shown in Figure 1:

$$
\tau=\tan \phi_{i} \sigma+C=\left(C / \sigma_{t}\right) \sigma+C
$$

where the cohesion, $C$, and the tensile strength, $\sigma_{t}$, are the line intercepts on the $\tau$ and the $\sigma$ axis, respectively. The angle of internal friction, $\phi_{i}$, is the slope angle of the yield line.

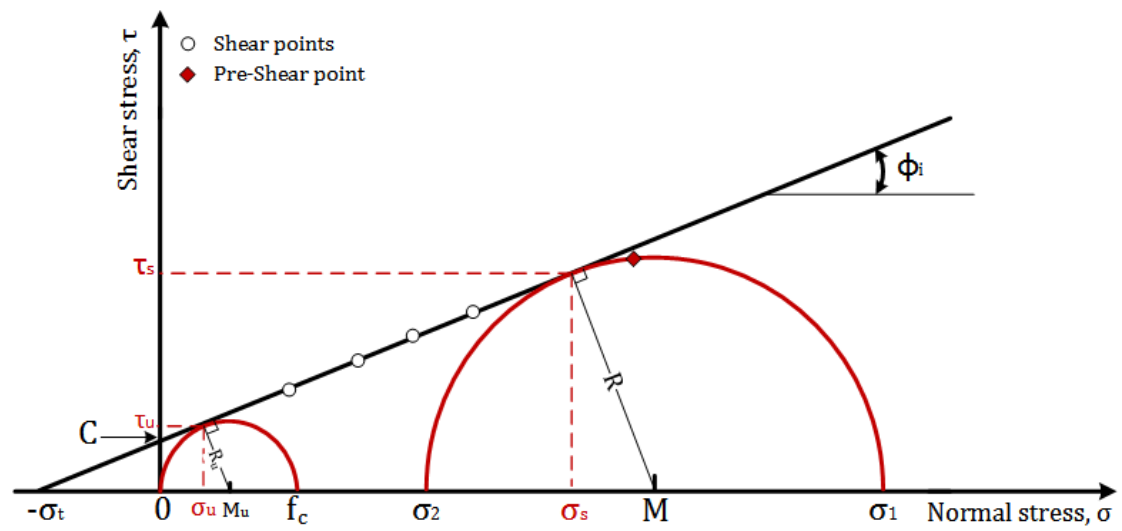

Figure 1. General linear YL and flow properties for a Coulomb material.

In the second approach, the yield locus can be described by a convex curved line expressed by the Warren-Spring equation (see Figure 2), in which the curvature index is represented by a dimensionless parameter of $n(1 \leq n \leq 2)$ :

$$
\tau=C\left(1+\sigma / \sigma_{t}\right)^{1 / n}
$$




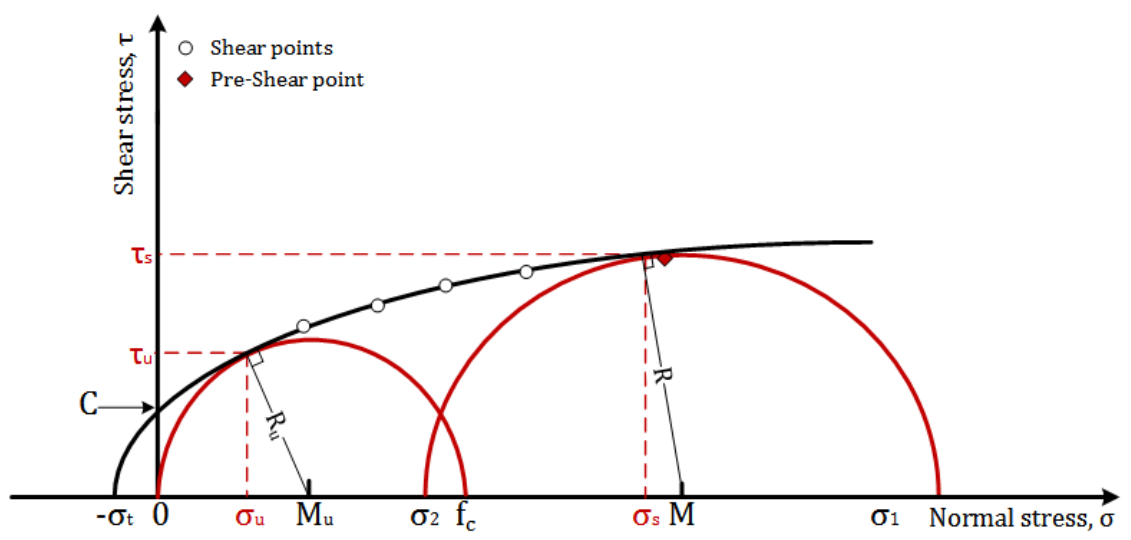

Figure 2. General curved YL and flow properties according to Warren-Spring equation.

With the Warren-Spring equation, the possibility to adapt the yield locus curvature allows for a better match between the yield locus and the experimental data. Furthermore, according to the experiments proposed by Ashton et al. [18] and by Triñanes et al. [10], the estimate of the tensile strength obtained with the application of this equation is quite close to the directly measured experimental values. Unfortunately, due to its non-linearity, the regression procedure for the Warren-Spring equation is much more complicated than for the Coulomb equation.

In this work, a procedure was developed to programmatically estimate the best-fitting parameters of the Warren-Spring equation. In order to understand the practical advantage of using this equation, this procedure was applied to a reasonably large number of experimental data, to calculate the effective angle of internal friction and the material flow function. These resulting properties were compared with the same values obtained with the application of the Coulomb equation, by neglecting any possible yield locus curvature.

Different types of Schulze shear cells $[14,19,20]$ were used to measure the experimental values of the material yield loci. Furthermore, since the flowability of powders can be affected by operative conditions and particle properties (such as temperature, size and shape $[15,21-24]$ ), experiments carried out with various materials with different particle shapes, density and particle size distributions between ambient temperature and $500{ }^{\circ} \mathrm{C}$ were considered.

\section{Methodology}

A Schulze Ring Shear Tester RST-01 (Dietmar-Schulze, Wolfenbüttel, Germany) was used as a reference apparatus [19] to characterize the flow properties of different materials at various temperatures. The experimental procedure used to evaluate the flow properties of the material follows the standard shear-tests technique proposed by Schulze [1] and reported in the American Society for Testing and Materials Standard D6773-2002 [25]. In general, the test procedure follows two steps: pre-shearing and shearing phases. For all the tests, at least 4 shear points were registered to obtain a yield locus, and a software application developed in the LabVIEW environment (LabView 2019, National Instrument, Austin, TX, USA) was used to acquire, visualize and record the data measured during the shear experiments.

As mentioned above, Coulomb materials are those for which a line can represent the yield locus. The slope and the intercept of this line represented by Equation (1) are estimated by a fitting procedure using the $(\sigma, \tau)$ experimental yield points obtained after pre-shearing the material at a specific applied normal stress.

In the proposed procedure, the best-fitting straight line through the experimental data is estimated by using the MatLab (Mathworks, Natick, MA, USA) routine polyfit, which enables to find the coefficients of a generic polynomial, $\mathrm{P}_{\mathrm{X}}$, of specific degree, $\mathrm{N}$, that best fits the input data in a least-squares sense. In the case when $N=1$, the output coefficients $P_{1}$ and $P_{2}$ are considered. All the 
linear yield locus parameters expressed by Equation (1) can be calculated as a function of the polynomial coefficients:

$$
\begin{gathered}
C=\mathrm{P}_{2} \\
\sigma_{t}=\mathrm{P}_{2} / \mathrm{P}_{1} \\
\phi_{i}=\arctan \left(\mathrm{P}_{1}\right)
\end{gathered}
$$

Regarding the curved yield locus, expressed by Equation (2), the best fitting line through the experimental data is estimated by minimizing the root-mean-square error (RMSE method). In order to perform the RMSE, the MatLab routine fmincon is used. This routine is based on the method of Lagrange multipliers, which enables users to solve general minimization problems subjected to constraints. In this case, the problem consisted in finding the values of Warren-Spring parameters, which can provide the minimum value for RMSE. This problem is subjected to one constraint only, in the space of the curve parameters, which is that the curvature index, $n$, must be in the range $1 \leq n \leq 2$. Final values of the non-linear regression procedure may depend on the initial values adopted for the calculation. In all the cases, this latter was set to the values obtained by assuming a linear yield locus $(n=1)$.

In order to compare results in terms of the most significant flow properties, in both the regression cases, the major principal stress during consolidation, $\sigma_{1}$, is calculated by the intersection of the $\sigma$-axis and the Mohr circle tangent to the yield locus and passing through the point ( $\left.\sigma_{\text {pre }}, \tau_{\text {pre }}\right)$, which is representative of the pre-shear stresses. The tangent point between the Mohr circle and the yield locus, as well as the Mohr circle radius and center, is calculated according to tangency condition between a line and a circle. In particular, the first-order Taylor series approximation of the Warren-Spring curve about the tangent point is used to obtain a linear function.

Similarly, the unconfined yield strength, $f_{\mathrm{c}}$, representing the state of stress in the unconfined material at yield, is estimated by the intersection of the $\sigma$-axis and the Mohr circle tangent to the yield locus and passing through the origin of the axis.

The solution code was implemented in Matlab software, using the App Designer Environment, and a specific MatLab App was created and named cYield [26]. It can be used in any MatLab environment, and it can be freely downloaded at https://uk.mathworks.com/matlabcentral/fileexchange/60998-cyield.

Figures 3 and 4 present the code structure and the view of this app. There are three sub-processes within the general code process, identified by the push-button bearing the corresponding name:

1. Linear $\mathrm{YL}$, which allows for the generation of a linear yield locus, the related consolidation Mohr circle and the related unconfined yield Mohr circle, starting from experimental data;

2. Warren-Spring, which allows for the generation of the curved yield locus, the related consolidation Mohr circle and the related unconfined yield Mohr circle, starting from experimental data;

3. Compare, which allows for the comparing of the results obtained by the two previous approaches. 


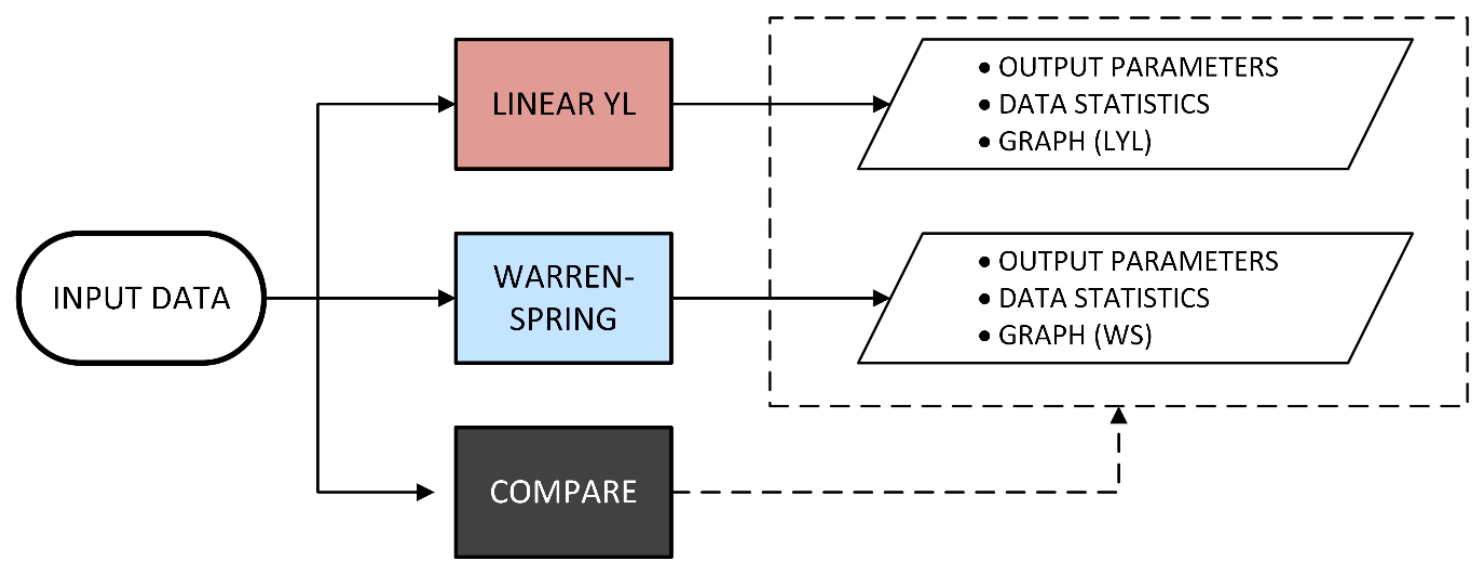

Figure 3. Structure of the general code process.

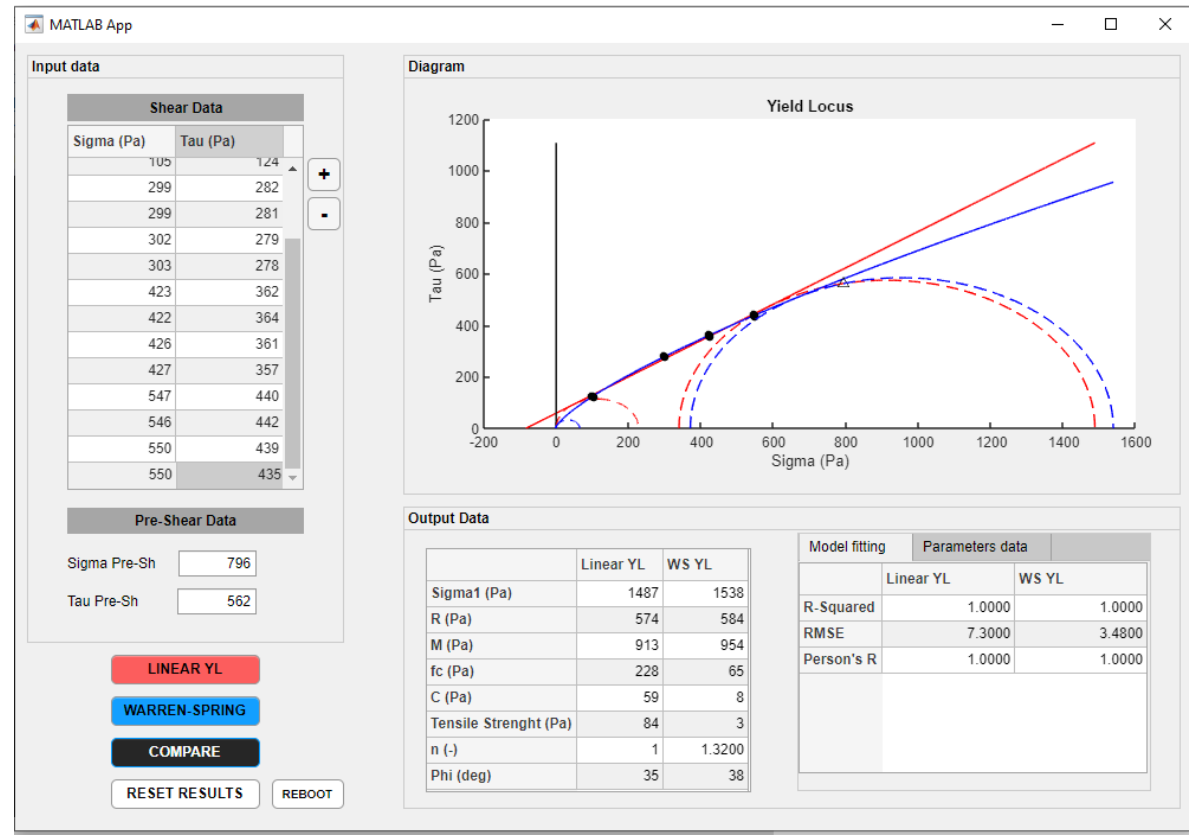

Figure 4. CYield App general view reporting, as an example, the use of the experimental results for the sample CP2 at the pre-shear load of $0.614 \mathrm{~kg}$.

Figures 5 and 6 report the structure of the two yield loci regression sub-processes procedures. Each sub-process needs all the sets of experimental couples made by the $(\sigma, \tau)$ shear data points and $\left(\sigma_{\text {pre, }}\right.$ $\left.\tau_{\text {pre}}\right)$ pre-shear data points. These values are used as input data for the subprocess that returns the main bulk flow properties and the statistics data as output. In particular, the coefficient of determination (R-squared), the root-mean-square error (RMSE) and Pearson's coefficient are reported as statistical indexes of the fitting process. 


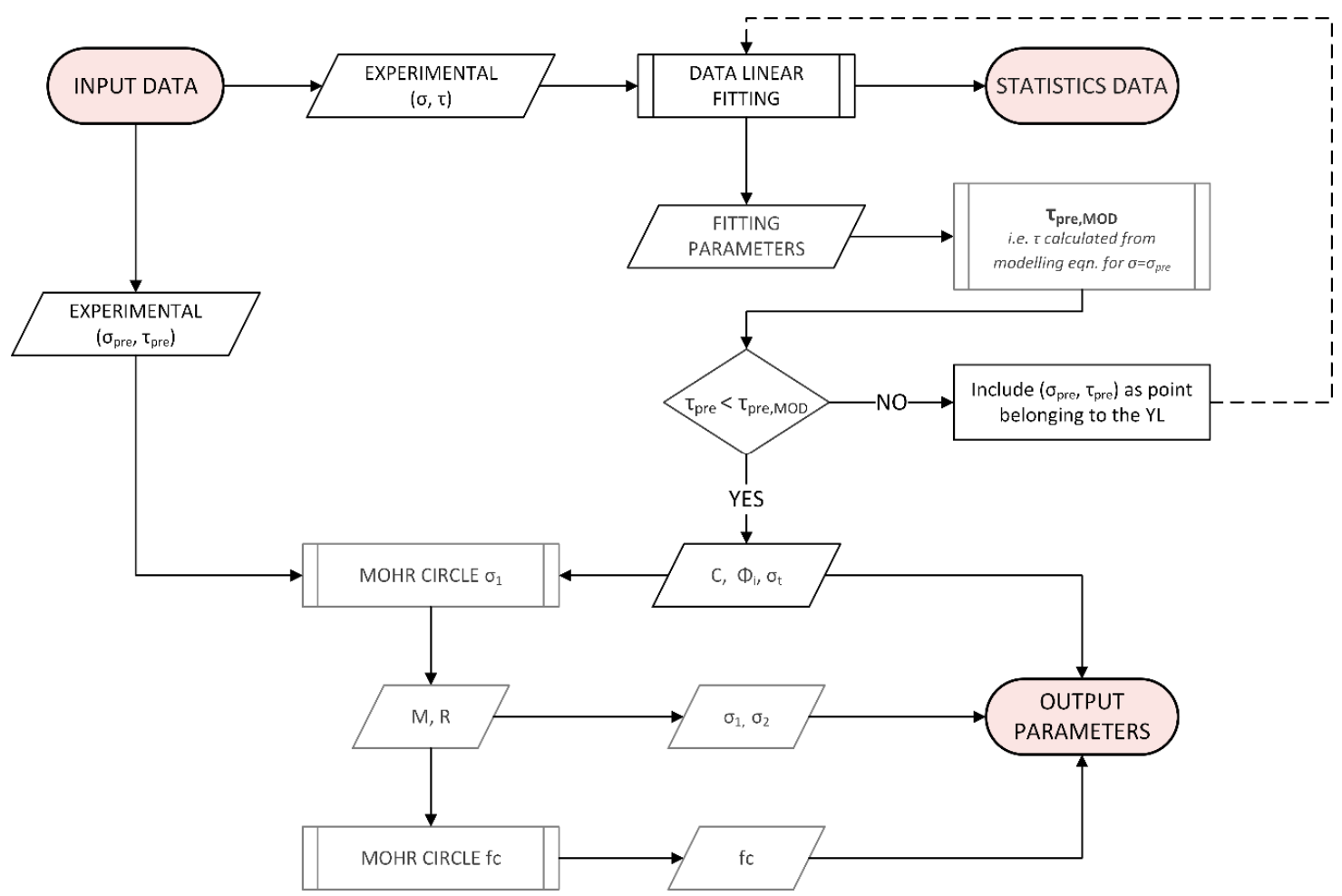

Figure 5. Linear YL sub-process structure.

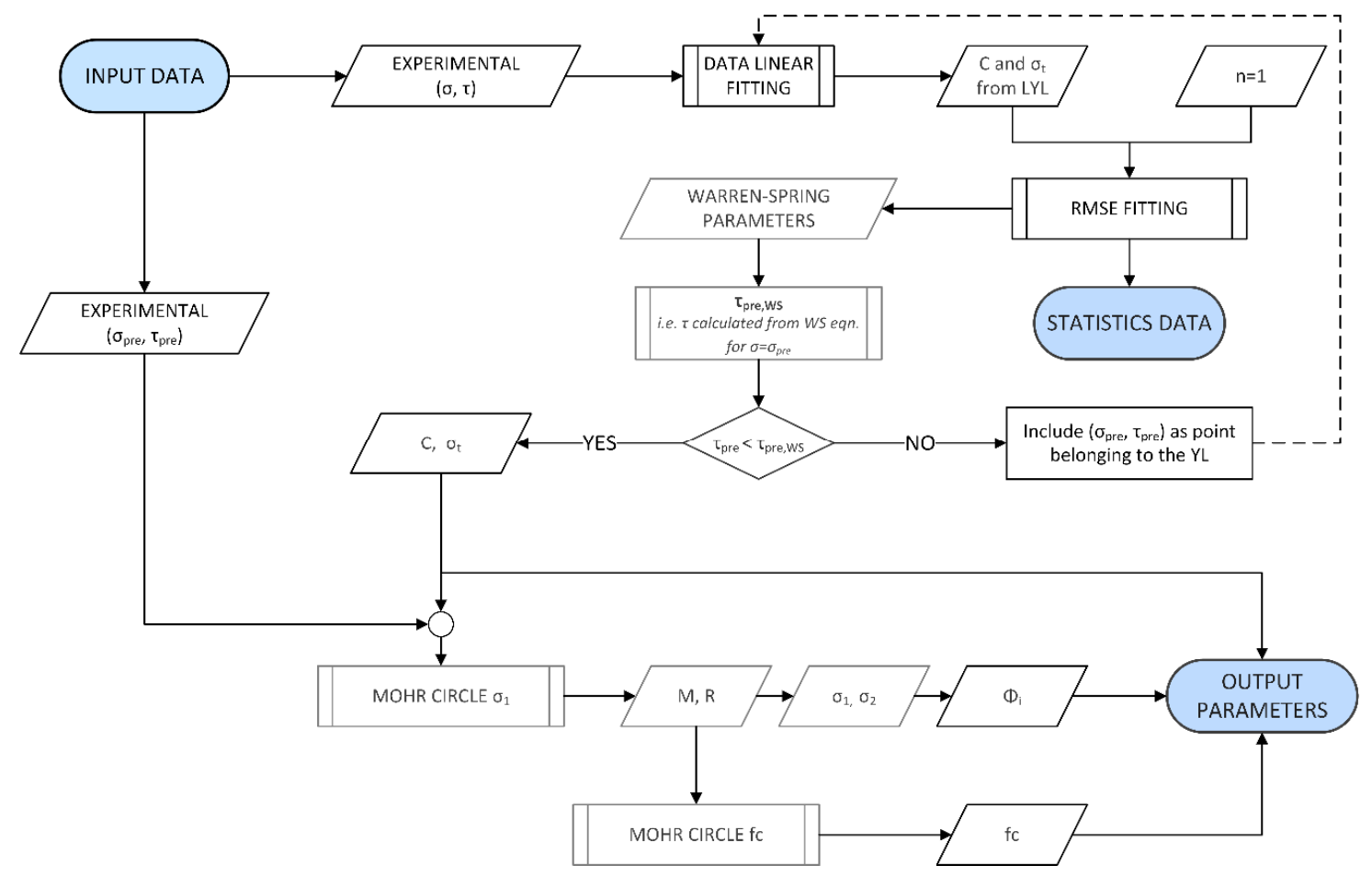

Figure 6. Warren-Spring sub-process structure.

The sub-processes' structures are presented below. Figures 5 and 6 show the structure of the sub-process Linear YL and the sub-process Warren-Spring, respectively.

As discussed in the previous section, the fitting procedure for the Warren-Spring yield locus is more complicated than the linear case, and data from linear fitting are used as the starting point for the analysis. 
A similar approach to the one presented above was proposed in 2010 by Peleg et al. [27]. In particular, they realized an interactive software for calculating the principal stresses of compacted cohesive powders with the Warren-Spring equation. In their application, however, they forced the contact point between the yield locus with the major Mohr circle to be coincident with the pre-shear representing point $\left(\sigma_{\text {pre, }} \tau_{\text {pre }}\right)$.

Instead, in this work, the pre-shear representing point ( $\left.\sigma_{\text {pre }}, \tau_{\text {pre }}\right)$ is considered to belong to the yield locus only in the case in which the resulting model value for the yield locus, $\tau$, at $\sigma_{\text {pre }}$ is larger than the experimental value, $\tau_{\text {pre. }}$ Such an approach is well described elsewhere [28], and it is also highlighted in Figures 5 and 6, where hyphenated lines report the repeated procedure applied in case the condition mentioned above on $\tau_{\text {pre }}$ is met.

\section{Data Analysis Using cYield}

Four different experimental materials, namely a ceramic powder, a rutile powder, a calcium carbonate powder and a dolomitic lime powder, were chosen in order to test the software outcomes. In particular, five cuts of the ceramic powders were considered, each characterized by a different particle size distribution.

The properties of these materials are listed in Table 1, including particle bulk densities, Sauter mean diameters $\left(d_{s v}\right)$ and particle size distributions by weight (PSD). Bulk densities were calculated from data supplied from the Schulze shear tester. PSDs and $d_{s v}$ were measured by a laser scattering particle size analyzer (Mastersizer 2000, Malvern Panalytical Ltd., Malvern, UK), and the 10th, the 50th and the 90th percentile sizes $\left(d_{10}, d_{50}\right.$ and $d_{90}$, respectively) are reported.

Table 1. Samples' main properties.

\begin{tabular}{lccccc}
\hline Sample & $\rho_{\boldsymbol{b}} \mathbf{( \mathbf { k g } / \mathbf { m } ^ { \mathbf { 3 } } )}$ & $\boldsymbol{d}_{\mathbf{1 0}}(\boldsymbol{\mu \mathrm { m } )}$ & $\boldsymbol{d}_{\mathbf{5 0}}(\boldsymbol{\mu \mathrm { m } )}$ & $\boldsymbol{d}_{\mathbf{9 0}}(\boldsymbol{\mu \mathrm { m } )}$ & $\boldsymbol{d}_{\boldsymbol{s v}}(\boldsymbol{\mu m})$ \\
\hline Ceramic Powder (CP1) & 700 & 3 & 12 & 28 & 7 \\
Ceramic Powder (CP2) & 1000 & 18 & 35 & 61 & 22 \\
Ceramic Powder (CP3) & 1200 & 38 & 61 & 95 & 41 \\
Ceramic Powder (CP4) & 1350 & 55 & 87 & 130 & 51 \\
Ceramic Powder (CP5) & 1400 & 90 & 184 & 423 & 104 \\
Rutile (RU) & 2300 & 91 & 205 & 444 & 146 \\
Calcium Carbonate (CaC) & 500 & 2 & 7 & 40 & 4 \\
Dolomitic Lime (DL) & 1000 & 2 & 23 & 257 & 6 \\
\hline
\end{tabular}

Table 2 reports the flow properties (namely, cohesion $C$, unconfined yield strength $f_{c}$ and material flowability $f f c=\sigma_{1} / f c$ ) obtained for all the samples considered at the various consolidation levels, as a function of the model yield locus. Moreover, values of the extrapolated isostatic tensile strength, $\sigma_{\mathrm{t}}$, and the Warren-Spring coefficient, $n$, are reported, as well. The flow functions obtained for all the samples are displayed in Figure 7, where the flow functions obtained by using the linear yield locus model are compared to those obtained through the Warren-Spring model. 
Table 2. Values of mean flow properties as function of the model yield locus.

\begin{tabular}{|c|c|c|c|c|c|c|c|c|c|c|c|}
\hline \multirow{2}{*}{ Sample } & \multirow{2}{*}{$\begin{array}{l}\text { Pre-Shear } \\
\text { Load } \\
\text { (kg) }\end{array}$} & \multirow{2}{*}{$\begin{array}{l}\text { Number of } \\
\text { Repetitions } \\
\text { Per Point }\end{array}$} & \multicolumn{4}{|c|}{ Linear Yield Locus } & \multicolumn{5}{|c|}{ Warren-Spring } \\
\hline & & & $\begin{array}{c}C \\
(\mathbf{P a})\end{array}$ & $\begin{array}{c}f_{c} \\
(\mathbf{P a})\end{array}$ & $\begin{array}{c}\sigma_{1} \\
(\mathbf{P a})\end{array}$ & $\begin{array}{c}\sigma_{\mathrm{t}} \\
(\mathbf{P a})\end{array}$ & $\begin{array}{c}C \\
(\mathbf{P a})\end{array}$ & $\begin{array}{c}f_{c} \\
(\mathbf{P a})\end{array}$ & $\begin{array}{c}\sigma_{1} \\
(\mathbf{P a})\end{array}$ & $\begin{array}{c}\sigma_{\mathrm{t}} \\
(\mathrm{Pa})\end{array}$ & $n(-)$ \\
\hline \multirow{4}{*}{$\mathrm{CP} 1$} & 0.414 & 4 & 191 & 719 & 1132 & 283 & 122 & 731 & 1126 & 31 & 2.00 \\
\hline & 0.514 & 4 & 230 & 857 & 1397 & 346 & 161 & 891 & 1392 & 45 & 2.00 \\
\hline & 0.614 & 4 & 250 & 963 & 1619 & 355 & 181 & 1006 & 1646 & 52 & 1.98 \\
\hline & 0.714 & 4 & 284 & 1075 & 1866 & 415 & 180 & 1081 & 1877 & 49 & 1.92 \\
\hline \multirow{4}{*}{$\mathrm{CP} 2$} & 0.414 & 4 & 57 & 214 & 1036 & 84 & 21 & 121 & 1046 & 11 & 1.31 \\
\hline & 0.514 & 4 & 58 & 220 & 1265 & 86 & 27 & 140 & 1274 & 18 & 1.25 \\
\hline & 0.614 & 4 & 59 & 228 & 1487 & 84 & 8 & 65 & 1538 & 3 & 1.32 \\
\hline & 0.714 & 4 & 73 & 280 & 1741 & 106 & 34 & 173 & 1765 & 24 & 1.22 \\
\hline \multirow{4}{*}{$\mathrm{CP} 3$} & 0.414 & 4 & 31 & 116 & 1031 & 47 & 15 & 69 & 1038 & 15 & 1.13 \\
\hline & 0.514 & 4 & 38 & 145 & 1289 & 57 & 25 & 106 & 1298 & 25 & 1.11 \\
\hline & 0.614 & 4 & 41 & 157 & 1498 & 60 & 25 & 112 & 1521 & 24 & 1.13 \\
\hline & 0.714 & 4 & 53 & 203 & 1756 & 78 & 34 & 146 & 1772 & 34 & 1.12 \\
\hline \multirow{4}{*}{$\mathrm{CP} 4$} & 0.414 & 4 & 16 & 60 & 1006 & 23 & $>1$ & $<1$ & 1010 & $>1$ & 1.10 \\
\hline & 0.514 & 4 & 38 & 143 & 1279 & 56 & 38 & 143 & 1279 & 56 & 1.00 \\
\hline & 0.614 & 4 & 31 & 120 & 1462 & 45 & 23 & 96 & 1470 & 27 & 1.06 \\
\hline & 0.714 & 4 & 31 & 116 & 1670 & 45 & 15 & 65 & 1679 & 16 & 1.08 \\
\hline \multirow{4}{*}{ CP5 } & 0.414 & 4 & 17 & 67 & 1007 & 24 & $<1$ & 1 & 1008 & $<1$ & 1.10 \\
\hline & 0.514 & 4 & 18 & 71 & 1241 & 26 & 7 & 33 & 1242 & 8 & 1.07 \\
\hline & 0.614 & 4 & 20 & 77 & 1461 & 27 & 9 & 38 & 1467 & 9 & 1.07 \\
\hline & 0.714 & 4 & 25 & 96 & 1689 & 36 & $<1$ & $<1$ & 1701 & $<1$ & 1.11 \\
\hline \multirow{3}{*}{ RU } & 0.514 & 4 & 23 & 88 & 1271 & 32 & 0.03 & $<1$ & 1273 & $<1$ & 1.12 \\
\hline & 0.614 & 4 & 15 & 61 & 1498 & 20 & 0.07 & $<1$ & 1503 & $<1$ & 1.08 \\
\hline & 0.714 & 4 & 15 & 59 & 1718 & 20 & 0.05 & $<1$ & 1720 & $<1$ & 1.05 \\
\hline \multirow{7}{*}{$\mathrm{CaC}$} & 1.6 & 2 & 330 & 1259 & 1614 & 477 & 260 & 1285 & 1597 & 96 & 1.90 \\
\hline & 3.2 & 2 & 654 & 2588 & 3321 & 889 & 470 & 2653 & 3277 & 129 & 2.00 \\
\hline & 4.8 & 2 & 976 & 3887 & 5021 & 1310 & 698 & 3989 & 4955 & 188 & 2.00 \\
\hline & 6.4 & 2 & 1178 & 4686 & 6237 & 1586 & 758 & 4772 & 6146 & 177 & 2.00 \\
\hline & 7.9 & 2 & 1558 & 6314 & 8694 & 2032 & 1122 & 6460 & 8611 & 323 & 1.92 \\
\hline & 9.5 & 2 & 1807 & 7364 & 10196 & 2335 & 1232 & 7517 & 10075 & 321 & 1.94 \\
\hline & 11.1 & 2 & 2114 & 8753 & 12335 & 2664 & 1303 & 8936 & 12200 & 268 & 2.00 \\
\hline \multirow{7}{*}{ DL } & 1.6 & 2 & 283 & 1043 & 1503 & 437 & 177 & 1036 & 1488 & 46 & 2.00 \\
\hline & 3.2 & 2 & 432 & 1606 & 2794 & 652 & 95 & 1381 & 2768 & 8 & 2.00 \\
\hline & 4.8 & 2 & 575 & 2109 & 4051 & 894 & 15 & 1473 & 4030 & $<1$ & 1.96 \\
\hline & 6.4 & 2 & 675 & 2472 & 5281 & 1051 & 46 & 1508 & 5264 & 2 & 1.86 \\
\hline & 7.9 & 2 & 872 & 3275 & 6809 & 1295 & 175 & 2412 & 6778 & 19 & 1.83 \\
\hline & 9.5 & 2 & 932 & 3544 & 8167 & 1354 & 297 & 2635 & 8138 & 62 & 1.69 \\
\hline & 11.1 & 2 & 1042 & 3869 & 9355 & 1580 & 15 & 1290 & 9362 & $<1$ & 1.75 \\
\hline
\end{tabular}




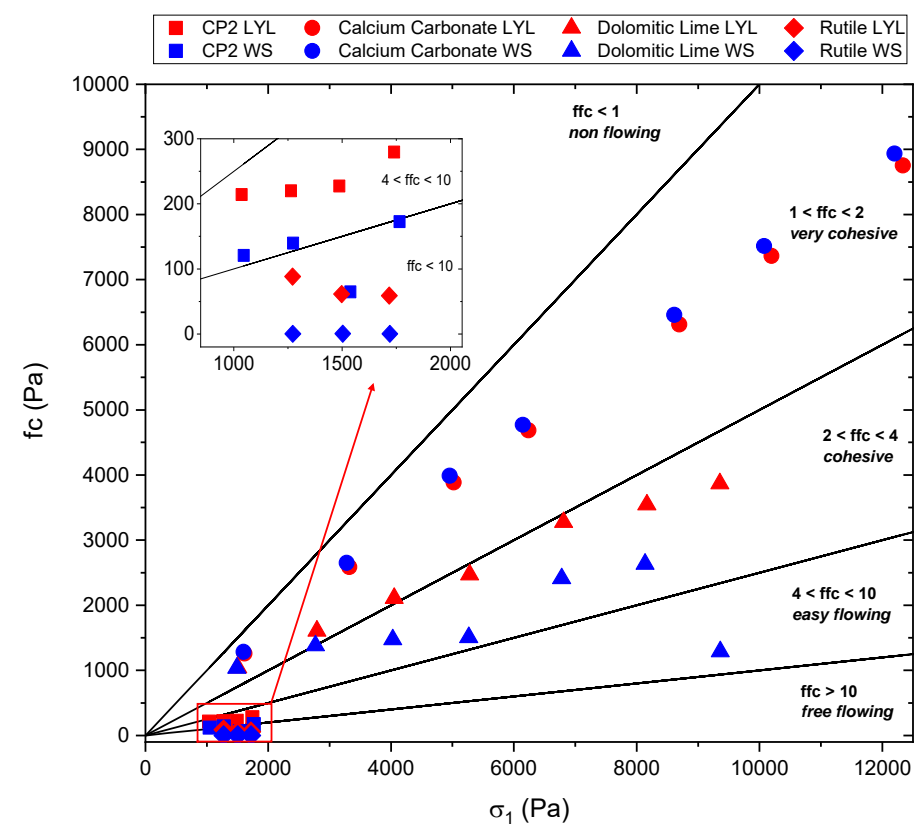

Figure 7. Comparison between the flow functions evaluated with the two different model yield loci.

Figure 8 presents some examples of the application of the app developed on four different samples. They allow visualizing the differences between the two yield locus models, with particular focus to the flow properties. The tables next to each plot report the experimental values of the pre-shear and shear points, averaged between all the repetitions of the experiments at the same conditions for all tested materials. The number of repetitions of every point of the yield locus for each of the pre-shearing conditions explored is specified in Table 2.

In order to analyze the quality of the obtained outcomes, the values of the coefficient of determination, $R^{2}$, and the root-mean-square error (RMSE) are reported in Figures 9 and 10, respectively.

As expected, the flow function of the material is significantly affected by the yield locus model chosen. In particular, the use of the Warren-Spring equation improves the ability of the yield locus model to fit the experimental data for all the materials. When the Warren-Spring equation is used, higher values of R-square and lower values of the RMSE index are obtained. This is quite reasonable, as the Warren-Spring equation is based on three parameters (rather than two, as for linear YL) and thus it allows a better data regression.

In particular, the comparison between the values of the extrapolated tensile strength, $\sigma_{t}$, shows significant differences in the two cases. Therefore, it must be recognized that the extrapolation in the traction plane of the yield locus is a rather strong assumption, as it is not possible to consider shear data in the traction half-plane. Indeed, such an extrapolation does not certainly reflect the reality, as it may estimate an incorrect value of the tensile strength.

Meanwhile, in the case of linear yield locus, such a value is typically overestimated. The use of the Warren-Spring equation leads to considerably lower values of $\sigma_{t}$, and in some cases resulting in unrealistic values [24]. However, as demonstrated by García-Triñanes et al. [10], the Warren-Spring model is the only model capable of extracting with good agreement to the experimental evidence the flow parameters that characterize the non-linearity of cohesive powder yield loci. 


\section{CP2}

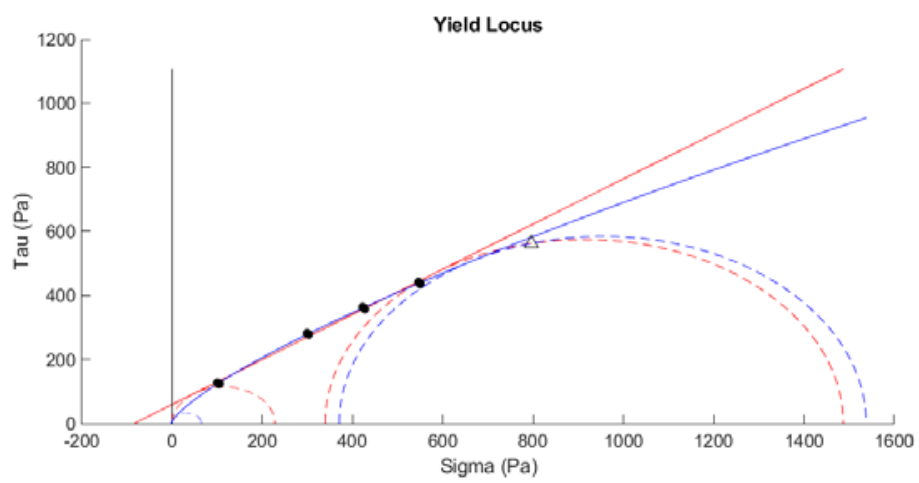

\section{RU}

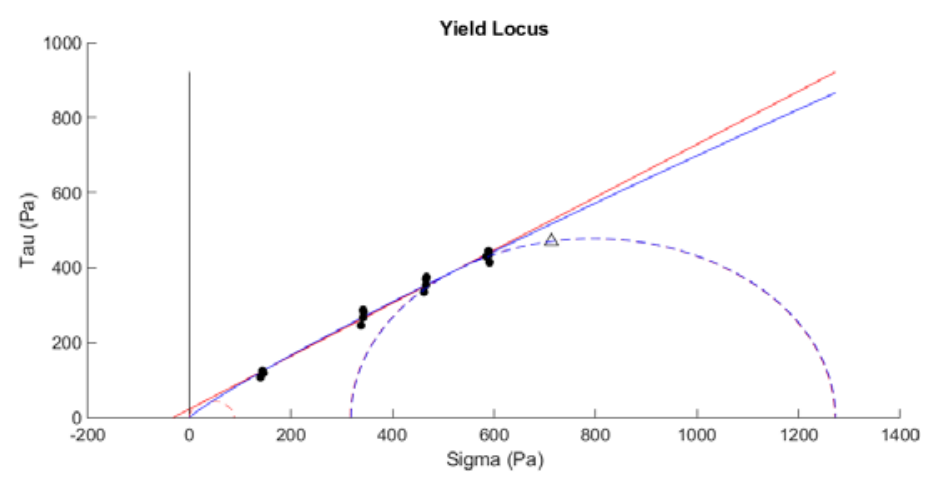

$\mathrm{CaC}$

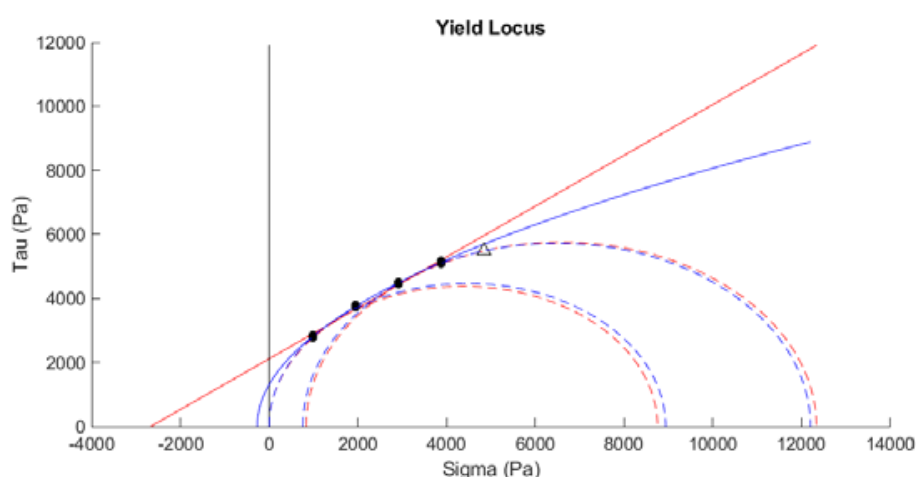

DL

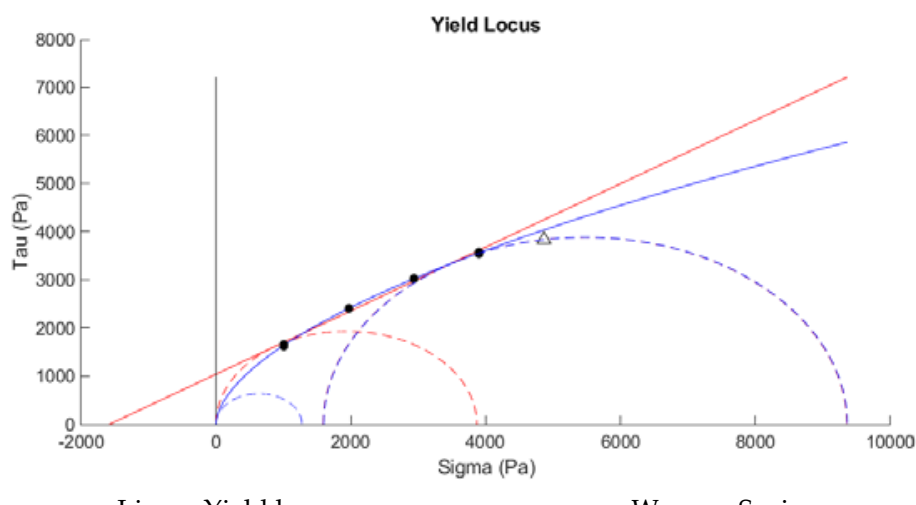

\begin{tabular}{|cc|}
\hline Pre-Shear Load: & $0.614 \mathrm{~kg}$ \\
\hline$\sigma_{\text {pre }}(\mathrm{Pa}): 796$ & $\tau_{\text {pre }}(\mathrm{Pa}): 562$ \\
\hline Shear points & \\
\hline$\sigma(\mathrm{Pa})$ & $\tau(\mathrm{Pa})$ \\
\hline $103 \pm 2$ & $125 \pm 2$ \\
\hline $301 \pm 2$ & $280 \pm 2$ \\
\hline $426 \pm 3$ & $361 \pm 3$ \\
\hline $548 \pm 2$ & $439 \pm 3$ \\
\hline
\end{tabular}

\begin{tabular}{|cc|}
\hline Pre-Shear Load: & $0.514 \mathrm{~kg}$ \\
\hline$\sigma_{\text {pre }}(\mathrm{Pa}): 713$ & $\tau_{\text {pre }}(\mathrm{Pa}): 470$ \\
\hline Shear points & \\
\hline$\sigma(\mathrm{Pa})$ & $\tau(\mathrm{Pa})$ \\
\hline $144 \pm 3$ & $119 \pm 7$ \\
\hline $341 \pm 2$ & $271 \pm 18$ \\
\hline $465 \pm 2$ & $358 \pm 18$ \\
\hline $589 \pm 3$ & $431 \pm 13$ \\
\hline
\end{tabular}

\begin{tabular}{|cc|}
\hline Pre-Shear Load: & $11.1 \mathrm{~kg}$ \\
\hline$\sigma_{\text {pre }}(\mathrm{Pa}): 4842$ & $\tau_{\text {pre }}(\mathrm{Pa}): 5479$ \\
\hline Shear points & \\
\hline$\sigma(\mathrm{Pa})$ & $\tau(\mathrm{Pa})$ \\
\hline $986 \pm 2$ & $2813 \pm 54$ \\
\hline $1949 \pm 2$ & $3761 \pm 52$ \\
\hline $2914 \pm 1$ & $4478 \pm 42$ \\
\hline $3878 \pm 2$ & $5124 \pm 65$ \\
\hline
\end{tabular}

\begin{tabular}{|cc|}
\hline Pre-Shear Load: & $11.1 \mathrm{~kg}$ \\
\hline$\sigma_{\text {pre }}(\mathrm{Pa}): 4863$ & $\tau_{\text {pre }}(\mathrm{Pa}): 3834$ \\
\hline Shear points & \\
\hline$\sigma(\mathrm{Pa})$ & $\tau(\mathrm{Pa})$ \\
\hline $1106 \pm 1$ & $1642 \pm 29$ \\
\hline $1971 \pm 2$ & $2411 \pm 6$ \\
\hline $2935 \pm 1$ & $3027 \pm 11$ \\
\hline $3899 \pm 1$ & $3556 \pm 28$ \\
\hline
\end{tabular}

- Experimental points

Figure 8. Yield locus plots and experimental data for four samples. 


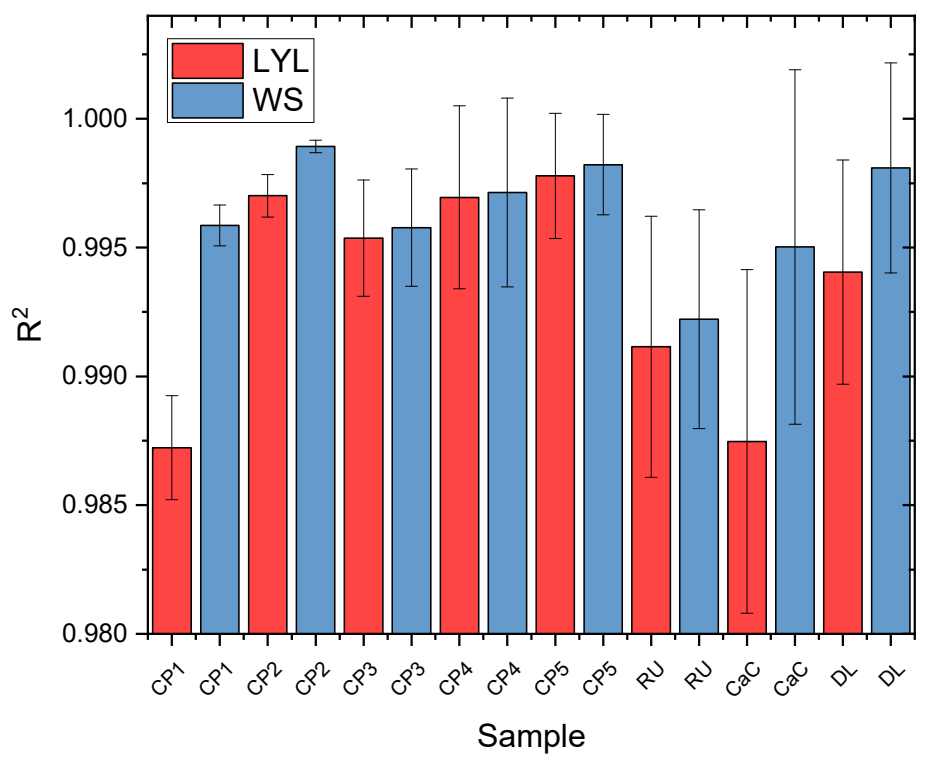

Figure 9. $R^{2}$ values for the investigated samples.
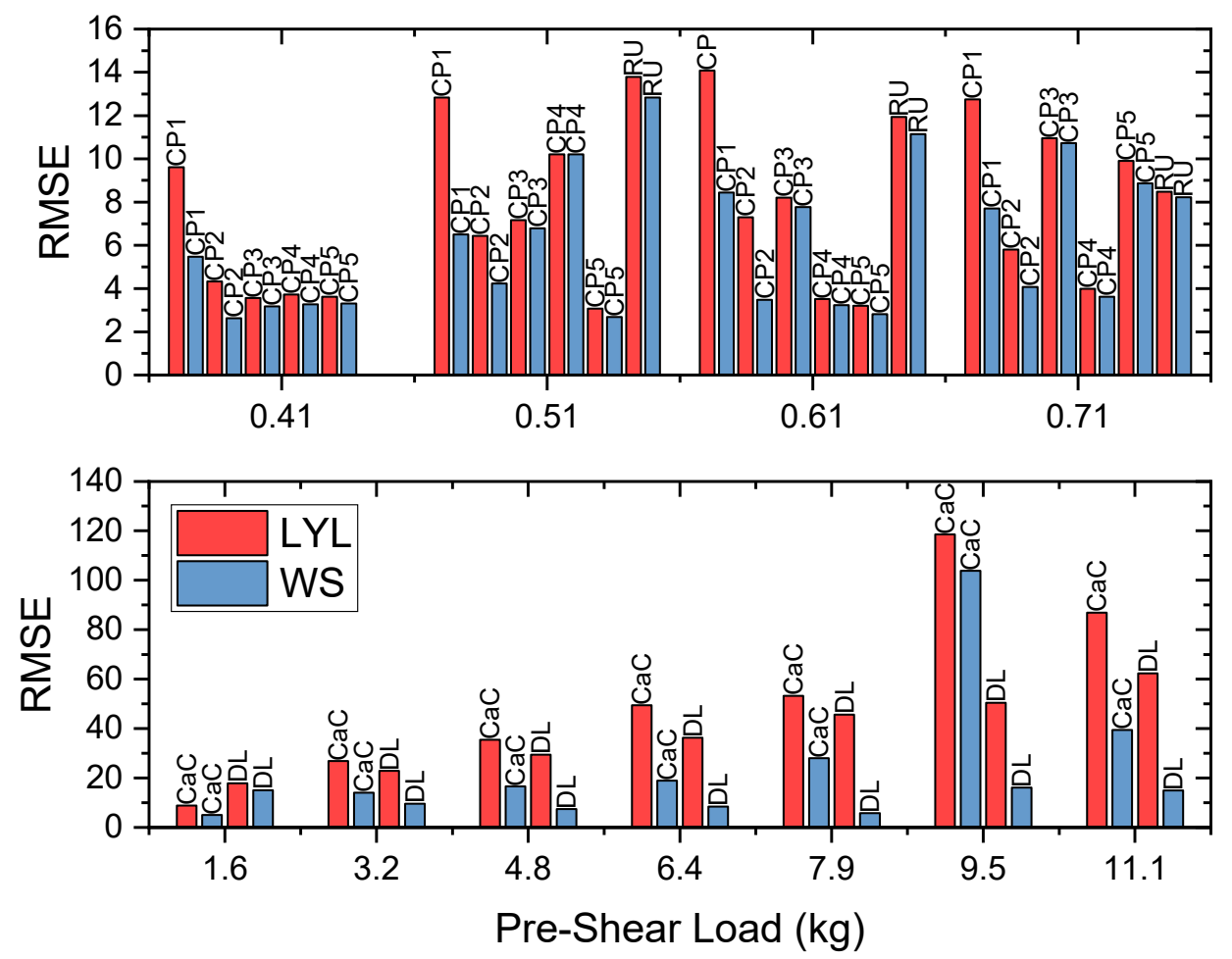

Figure 10. RMSE values for the investigated samples related to the pre-shear loads.

\section{Conclusions}

The interactive software developed in this work shows as the flow function, and thus the estimation of the flow properties of the material is critically affected by the choice of the yield locus equation. In particular, it has been highlighted how the use of the Warren-Spring equation significantly improves the fitting between modeling and experimental data, with higher values of $R$-square and lower values of the RMSE index than the linear case. This confirms the outcomes proposed by other authors, who also demonstrated that the flow behavior of many powders, especially if cohesive, can be accurately described by a non-linear yield locus. 
As major contribution, for the first, time to our knowledge, the approach proposed does not force the contact point between the yield locus with the major Mohr circle to be coincident with the pre-shear representing point $\left(\sigma_{\text {pre }}, \tau_{\text {pre }}\right)$, contrary to other software previously developed and presented in the literature.

Through the software, the user can easily handle experimental shear data and convert them into bulk flow properties, such as principal stresses, cohesion and angle of friction. Moreover, the user can directly visualize them, as well. The software offers a quick and easy way to process new shear analysis data, compare the results obtained by two different approaches and evaluate them from a statistic point of view.

This tool is then helpful for predicting and quantifying the response of particulate solids to external stresses, which makes it particularly valuable, since it can directly impact the performance and the efficiency of several manufacturing processes.

Author Contributions: Conceptualization, D.M. and R.C.; Methodology and Software, D.M., R.C. and D.S.; Data Analysis and Investigation, D.M., H.S. and M.M.; Resources, D.S., D.B. and M.P.; Writing-Original Draft Preparation, D.M. and R.C.; Writing-Review \& Editing, P.L., D.B. and M.P.; Supervision, P.L. and M.P. All authors have read and agreed to the published version of the manuscript.

Funding: This research received no external funding.

Conflicts of Interest: The authors declare no conflict of interest.

\section{References}

1. Schulze, D. Powders and Bulk Solids: Behavior, Characterization, Storage and Flow; Springer Science \& Business Media: Berlin, Gemany, 2007.

2. Janssen, H.A. Versuche uber Getreidedruck in Silozellen. Z. des Ver. Dtsch. Ing. 1895, 39, 1045-1049.

3. Carr, R.L. Evaluating flow properties of solids. Chem. Eng. 1965, 72, 163-168.

4. Molerus, O. Theory of yield of cohesive powders. Powder Technol. 1975, 12, 259-275. [CrossRef]

5. Nedderman, R.M. Statics and Kinematics of Granular Materials; Cambridge University Press: Cambridge, UK, 1992; ISBN 9780511600043.

6. Tomas, J. Assessment of Mechanical Properties of Cohesive Particulate Solids. Part 2: Powder Flow Criteria. Part. Sci. Technol. 2001, 19, 111-129. [CrossRef]

7. Fitzpatrick, J.J.; Barringer, S.A.; Iqbal, T. Flow property measurement of food powders and sensitivity of Jenike's hopper design methodology to the measured values. J. Food Eng. 2004, 61, 399-405. [CrossRef]

8. Schwedes, J. Review on testers for measuring flow properties of bulk solids. Granul. Matter 2003, 5, 1-43. [CrossRef]

9. Schmitt, R. Powders and Bulk Solids; Springer: Berlin, Germany, 2010; Volume 82, ISBN 9783540737674.

10. García-Triñanes, P.; Luding, S.; Shi, H. Tensile strength of cohesive powders. Adv. Powder Technol. 2019, 30, 2868-2880. [CrossRef]

11. Kono, H.; Aksoy, E.; Itani, Y. Measurement and application of the rheological parameters of aerated fine powders-A novel characterization approach to powder flow properties. Powder Technol. 1994, 81, 177-187. [CrossRef]

12. Bruni, G.; Lettieri, P.; Newton, D.; Barletta, D. An investigation of the effect of the interparticle forces on the fluidization behaviour of fine powders linked with rheological studies. Chem. Eng. Sci. 2007, 62, 387-396. [CrossRef]

13. Bruni, G.; Tomasetta, I.; Barletta, D. Sensitivity analysis on a rheological model for the flowability of aerated fine powders. Chem. Eng. Trans. 2009, 17, 735-740.

14. Tomasetta, I.; Barletta, D.; Poletto, M. The High Temperature Annular Shear Cell: A modified ring shear tester to measure the flow properties of powders at high temperature. Adv. Powder Technol. 2013, 24, 609-617. [CrossRef]

15. Macrì, D.; Poletto, M.; Barletta, D.; Sutcliffe, S.; Lettieri, P. Analysis of industrial reactive powders flow properties at high temperature. Powder Technol. 2017, 316, 131-138. [CrossRef] 
16. Valverde, J.M.; Castellanos, A.; Mills, P.; Quintanilla, M.A.S. Effect of particle size and interparticle force on the fluidization behavior of gas-fluidized beds. Phys. Rev. E Stat. Nonlin. Soft Matter Phys. 2003, 67, 051305. [CrossRef] [PubMed]

17. Walters, J.K. A theoretical analysis of stresses in axially-symmetric hoppers and bunkers. Chem. Eng. Sci. 1973, 28, 779-789. [CrossRef]

18. Ashton, M.D.; Cheng, D.C.H.; Farley, R.; Valentin, F.H.H. Some investigations into the strength and flow properties of powders. Rheol. Acta 1965, 4, 206-218. [CrossRef]

19. Schulze, D. Development and application of a novel ring shear tester-Entwicklung und Anwendung eines neuartigen Ringschergerätes. Aufbereit. Tech. 1994, 35, 524-535.

20. Schulze, D. A new ring shear tester for flowability and time consolidation measurements. In Proceedings of the 1st International Particle Technology Forum, Denver, CO, USA, 17-19 August 1994.

21. Fu, X.; Huck, D.; Makein, L.; Armstrong, B.; Willen, U.; Freeman, T. Effect of particle shape and size on flow properties of lactose powders. Particuology 2012, 10, 203-208. [CrossRef]

22. Tomasetta, I.; Barletta, D.; Poletto, M. The Effect of Temperature on Flow Properties of Fine Powders. Chem. Eng. Trans. 2011, 24, 655-660.

23. Tomasetta, I.; Barletta, D.; Poletto, M. Correlation of powder flow properties to interparticle interactions at ambient and high temperatures. Particuology 2014, 12, 90-99. [CrossRef]

24. Chirone, R.; Barletta, D.; Lettieri, P.; Poletto, M. Bulk flow properties of sieved samples of a ceramic powder at ambient and high temperature. Powder Technol. 2016, 288, 379-387. [CrossRef]

25. ASTM International. D6773-02: Standard Test Method for Bulk Solids Using Schulze Ring Shear Tester 1. Annu. B ASTM Stand. 2010, 1-26. [CrossRef]

26. Macri, D. cYield, MATLAB Central File Exchange. 2020. Available online: https://www.mathworks.com/ matlabcentral/fileexchange/60998-cyield (accessed on 15 April 2020).

27. Peleg, M.; Normand, M.D.; Corradini, M.G. Interactive software for calculating the principal stresses of compacted cohesive powders with the Warren-Spring equation. Powder Technol. 2010, 197, 268-273. [CrossRef]

28. Salehi, H.; Barletta, D.; Poletto, M. A comparison between powder flow property testers. Particuology 2017, 32, 10-20. [CrossRef]

(C) 2020 by the authors. Licensee MDPI, Basel, Switzerland. This article is an open access article distributed under the terms and conditions of the Creative Commons Attribution (CC BY) license (http://creativecommons.org/licenses/by/4.0/). 